New Drug Update

\title{
Expanding horizons of anticoagulant therapy: Dabigatran etexilate a novel oral anticoagulant
}

\author{
Pradeep Jadhav $^{1}$, Ipseeta Ray ${ }^{1}$, Alfven Vieira ${ }^{2}$, Jaishree Ghanekar ${ }^{3}$, Yeshwant A. Deshmukh ${ }^{1}$
}

\begin{abstract}
${ }^{1}$ Department of Pharmacology, MGM Medical College \& Hospital, Navi Mumbai, Maharashtra, India

${ }^{2}$ Department of Orthopaedics, MGM Medical College \& Hospital, Navi Mumbai, Maharashtra, India

${ }^{3}$ Department of Medicine, MGM Medical College \& Hospital, Navi Mumbai, Maharashtra, India
\end{abstract}

Received: 10 August 2013

Revised: 22 August 2013

Accepted: 24 August 2013

\section{*Correspondence to:}

Dr. Pradeep Jadhav,

Email: doc_pradeep@hotmail.com

(C) 2013 Jadhav P et al. This is an openaccess article distributed under the terms of the Creative Commons Attribution NonCommercial License, which permits unrestricted non-commercial use, distribution, and reproduction in any medium, provided the original work is properly cited.

\begin{abstract}
Thrombo-embolic disease is a major challenging clinical problem associated with significant mortality and morbidity. Anticoagulation with the existing heparin products and vitamin $\mathrm{K}$ antagonist (VKA) anticoagulants are still the mainstay of management. However, due to the risk of bleeding and well-documented drawbacks, the quest for a novel oral anticoagulant has led to the clinical development of dabigatran etexilate. Dabigatran etexilate is a direct thrombin (IIa) inhibitor which has recently been approved in India for prevention of venous thromboembolic events (VTE) in patients who have undergone major orthopaedic (total knee or hip replacement) surgery and for prevention of stroke, systemic embolism and reduction of vascular mortality in adult patients with atrial fibrillation. Thus dabigatran etexilate is a promising alternative to the current heparin products and VKAs in patients who require long-term oral anticoagulation.
\end{abstract}

Keywords: Dabigatran etexilate, Direct thrombin inhibitor, Novel anticoagulant, Stroke prevention, Atrial fibrillation, Venous thromboembolism, Orthopaedic surgery

\section{INTRODUCTION}

Anticoagulation is still the mainstay in the management of thrombo-embolic disorders. Advanced understanding of the cascade and molecular mechanisms of blood coagulation has led to the discovery of novel anticoagulants for the prevention and treatment of thrombo-embolic disorders in order to overcome the limitations of existing conventional heparin products and Vitamin $\mathrm{K}$ antagonists (VKA)., ${ }^{1,2}$ These limitations include bleeding complications, narrow therapeutic index, inter-individual patient variability, multiple drug and food interactions, longer half-life, lower patient compliance and need for regular anticoagulation laboratory monitoring which limits the clinical effectiveness and safety of conventional anticoagulants. ${ }^{2,3}$
Dabigatran etexilate a novel oral anticoagulant, which directly targets and inhibits thrombin, is the focus of research. Dabigatran has several advantages, which includes target specific action, better pharmacokinetic profile and predictable anticoagulant response, without the need for therapeutic monitoring. ${ }^{2-6}$ Dabigatran etexilate has been evaluated for its safety and efficacy in several large-scale clinical trials. This article highlights the pharmacology, clinical evidences and regulatory status of Dabigatran etexilate with current approved indications in India.

PHARMACOLOGY: DABIGATRAN ETEXILATE

Chemical structure ${ }^{2}$ 
Dabigatran etexilate is the orally active prodrug of the molecule "Dabigatran" (Figure 1). Dabigatran belongs to a new structural class of non-peptidic inhibitors employing a trisubstituted benzimidazole as the central scaffold and 4-amidinophenylalanine as a mimetic of arginine which exhibits a specific, competitive, and reversible inhibition of thrombin. ${ }^{2,4-6}$

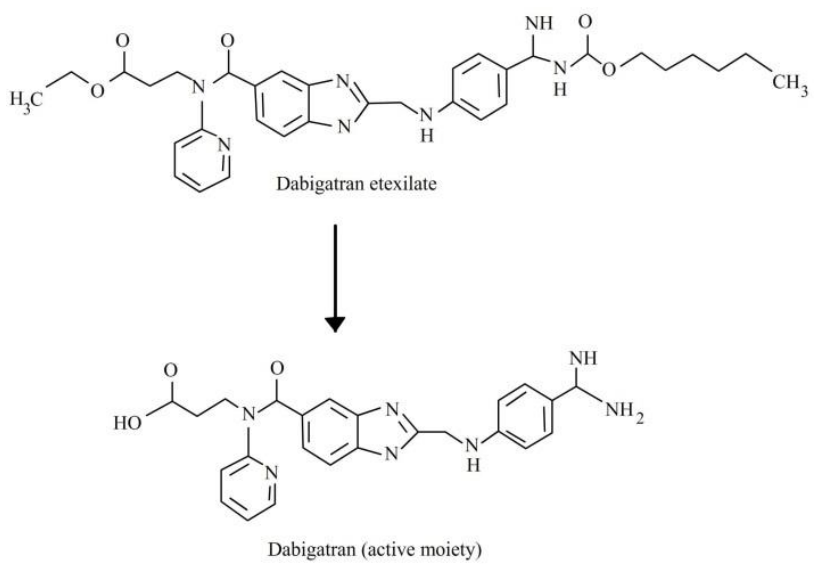

Figure 1: Chemical structure of dabigatran etexilate and its active moiety.

\section{Mechanism of action}

Thrombin plays a key central role in the blood coagulation cascade. Targeted inhibition of thrombin within the coagulation cascade not only attenuates fibrin formation, but also reduces thrombin generation and limits platelet activation. Dabigatran is a novel direct thrombin (IIa) inhibitor. It is a potent, non-peptidic molecule, competitive and reversible inhibitor of thrombin which exhibits a strong thrombin inhibitory activity as well as has a high selectivity to thrombin. ${ }^{5,6}$ It is effective in inhibiting both circulating and clot-bound thrombin. ${ }^{5,6}$ By inhibiting thrombin, Dabigatran prevents the conversion of fibrinogen into fibrin, positive feedback amplification of coagulation activation, cross-linking of fibrin monomers, platelet activation, and inhibition of fibrinolysis. $^{7}$

\section{Pharmacokinetics}

Dabigatran etexilate is a prodrug that is rapidly converted to active moiety "Dabigatran" in the blood and liver with peak plasma levels and maximal anticoagulant effects achieved in 2-3 hours following oral administration. The half-life $\left(\mathrm{t}^{1} / 2\right)$ of the drug ranges between 12-17 hours. The predictable pharmacokinetic profile of dabigatran supports a fixed-dose regimen without the need for routine coagulation. Dabigatran etexilate and dabigatran are neither metabolized by, nor induce or inhibit cytochrome P450 drug metabolizing enzymes. ${ }^{6,8}$

Dabigatran is predominantly excreted unchanged via the kidneys $(\sim 80 \%)$ with the remainder eliminated via the bile $^{7}$, thus reduced renal function results in elevated plasma levels and prolonged half-life. Patients with mild renal impairment, do not require dose adjustment while in moderate renal impairment (creatinine clearance 30-50 $\mathrm{mL} / \mathrm{min}$ ), lower dose can be used. However it is absolutely contraindicated in patients with severe renal impairment (creatinine clearance less than $30 \mathrm{~mL} / \mathrm{min}$ ). ${ }^{6,8}$

\section{CLINICAL TRIAL EVIDENCES}

\section{Stroke prevention in atrial fibrillation}

The clinical evidence for dabigatran etexilate in stroke prevention in atrial fibrillation (AF) has been established from landmark RE-LY ${ }^{9}$ trial. RE-LY was a phase III, multicenter, prospective, randomized, open-label, blinded, endpoint-adjudication trial in 18,113 patients with non-valvular AF at risk of stroke. ${ }^{9}$

RE-LY trial assessed the efficacy and safety of two fixed doses of dabigatran etexilate (110 or $150 \mathrm{mg}$ twice a day), with adjusted-dose warfarin targeted international normalized ratio (INR) of 2 to $3 .{ }^{9}$ Dabigatran etexilate $110 \mathrm{mg}$ twice a day was non-inferior to warfarin with respect to the primary end point of all stroke (ischemic or hemorrhagic) or systemic embolism, with event rates of $1.54 \%$ and $1.71 \%$ per year ${ }^{9}$, respectively (non-inferiority $\mathrm{P}<0.001)$ and $1.11 \%$ per year with dabigatran etexilate $150 \mathrm{mg}$ twice a day $(\mathrm{P}<0.001$ for superiority, $\mathrm{P}<0.001$ for non-inferiority). ${ }^{9,10,11}$ Dabigatran etexilate $150 \mathrm{mg}$ twice a day was superior to warfarin for preventing stroke of all types, ischemic (25\%) or hemorrhagic (74\%) stroke, disabling or fatal stroke, and death (15\%) from vascular causes. ${ }^{9-11}$

The events of major bleeding were significantly lower with dabigatran etexilate $110 \mathrm{mg}$ twice a day $(2.87 \%$ per year, $\mathrm{P}=0.003)$ compared with warfarin $(3.57 \%$ per year), whereas the events of major bleeding with dabigatran etexilate, $150 \mathrm{mg}$ twice a day (3.32\% per year) was similar to warfarin. ${ }^{9-11}$

Sub-analysis of RE-LY in Asian ${ }^{12}$ population, also demonstrates consistently superior efficacy of dabigatran etexilate $(150 \mathrm{mg})$ compared to warfarin. ${ }^{12}$

\section{Secondary prevention in acute coronary syndrome}

It has been evaluated in RE-DEEM ${ }^{13}$ study, phase II double-blind, placebo-controlled, dose-escalation study in patients with Acute Coronary Syndrome (ACS). Dabigatran etexilate in conjunction with (aspirin and clopidogrel) anti-platelet dual therapy significantly reduced coagulation activity in patients with recent myocardial infarction with a dose-dependent increase in bleeding events. ${ }^{13}$ Thus RE-DEEM study opened the doorway for a larger definitive phase 3 trial of dabigatran in prevention of recurrent events after ACS. It is uncertain whether a large phase 3 trial is being planned till date. 


\section{Primary prevention of venous thromboembolic (VTE) events}

The clinical evidences for dabigatran etexilate in primary prevention of VTE in major orthopaedic surgery have been established from RENOVATE ${ }^{14}$, REMODEL ${ }^{15}$, REMOBILIZE $^{16}$ and RENOVATE II $^{17}$ trials. The REMOBILIZE trial indicated that dabigatran etexilate $150 \mathrm{mg}$ or $220 \mathrm{mg}$ once daily over $12-15$ days of treatment, was not as effective to North American enoxaparin $30 \mathrm{mg}$ twice daily regimen in preventing total VTE and all-cause mortality in patients undergoing unilateral Total Knee Replacement (TKR) surgery. ${ }^{16,18}$ However, the REMODEL study demonstrated that over 6-10 days of treatment, dabigatran etexilate $150 \mathrm{mg}$ or $220 \mathrm{mg}$ once daily was non-inferior to enoxaparin $(40 \mathrm{mg}$ once daily) for the prevention of VTE in patients undergoing TKR surgery. ${ }^{15,18}$ The incidence of major bleeding and overall adverse events did not differ significantly between either dose of dabigatran etexilate and enoxaparin. ${ }^{15,18}$ In RE-NOVATE trial, similar findings were documented in patients who underwent Total Hip Replacement (THR) surgery and used extended VTE prophylaxis (for 28-35 days). ${ }^{1418}$ The RE-NOVATE II trial also demonstrated that extended prophylaxis with dabigatran etexilate $220 \mathrm{mg}$ once daily was as effective as subcutaneous enoxaparin $40 \mathrm{mg}$ once daily in reducing the risk of VTE after THR surgery, and superior to enoxaparin in reducing the risk of major VTE, with similar safety profiles. ${ }^{17,18}$

\section{Treatment and secondary prevention of venous thromboembolic events}

The clinical evidences for dabigatran etexilate in the treatment of acute VTE have been established from RECOVER $^{19}$ and RECOVER $\mathrm{II}^{20}$ trials. RECOVER ${ }^{19}$ was a randomized, double-blind, non-inferiority trial of dabigatran etexilate $150 \mathrm{mg}$ twice daily versus warfarin (target INR 2 to 3 ) in the treatment of acute VTE for 6 months. The trial reported that a fixed dose of dabigatran etexilate was as effective as warfarin in the treatment of acute VTE with hazard ratio in dabigatran for recurrent VTE 1.10 (95\% CI, 0.65 to 1.84 ) and had similar safety profile to that of warfarin. ${ }^{18,19}$ RE-COVER $\mathrm{II}^{20}$ as well documented and substantiated that, efficacy of dabigatran etexilate was non-inferior to warfarin with lower risk for major bleeding in the treatment of VTE for six months. ${ }^{18,20,21}$

Recently RE-MEDY ${ }^{22}$ and RE-SONATE ${ }^{22}$, two paired randomized study also demonstrated the effectiveness of extended use of dabigatran in the treatment of VTE. ${ }^{22,23}$

\section{REGULATORY STATUS}

U.S Food and Drug Administration (USFDA): On October 20, 2010, USFDA approved dabigatran etexilate $150 \mathrm{mg}$ BID for prevention of stroke in patients with
$\mathrm{AF}^{24}$ It is not yet approved for the prevention and treatment of acute VTE in United States.

European Medicines Agency (EMA): On March 18, 2008, EMA approved dabigatran etexilate for the prevention of thromboembolic disease following hip or knee replacement surgery and in August 2011 approved it for prevention of stroke in non-valvular $\mathrm{AF}$ patients. ${ }^{25}$ Currently, dabigatran etexilate is under process for approval in acute VTE and prevention of recurrent VTE.

Drug Controller General of India (DCGI): On December 2011, DCGI approved dabigatran etexilate for prevention of stroke in patients with $\mathrm{AF}^{26}$ Recently on 11th February 2013, it got approved for primary prevention of VTE after major orthopaedic surgery. ${ }^{26}$

\section{INDICATIONS}

\section{Approved indications in India are $e^{26}$}

1. Dabigatran etexilate is indicated for prevention of stroke, systemic embolism and reduction of vascular mortality in adult patients with $\mathrm{AF}^{26}$

2. Dabigatran etexilate is indicated for prevention of VTE events in patients who have undergone major orthopaedic (total knee or hip replacement) surgery. ${ }^{26}$

\section{DOSAGE AND ADMINISTRATION}

\section{Dose-Adults $^{27-30}$}

1. Prevention of stroke in AF: The recommended daily dose of Dabigatran etexilate is $300 \mathrm{mg}$ taken orally as $150 \mathrm{mg}$ hard capsules twice daily $(75 \mathrm{mg}$ twice a day for patients with moderate renal impairment $30-50 \mathrm{~mL} / \mathrm{min}$ creatinine clearance). ${ }^{27-30}$

2. Prevention of VTE after major orthopaedic surgery: The recommended dose of Dabigatran etexilate is $220 \mathrm{mg}$ once daily taken as 2 capsules of $110 \mathrm{mg}$. (Patients with moderate renal impairment have an increased risk for bleeding, the recommended dose is $150 \mathrm{mg}$ once a day, taken as 2 capsules of $75 \mathrm{mg}$ ). ${ }^{27-30}$

A. Prevention of VTE following knee replacement surgery: Starting dose of $110 \mathrm{mg} \mathrm{1-4}$ hours after surgery and continued with $220 \mathrm{mg}$ once daily thereafter for a total of 10 days. ${ }^{27-30}$

B. Prevention of VTE following hip replacement surgery: Starting dose of $110 \mathrm{mg} \mathrm{1-4}$ hours after surgery and continued with $220 \mathrm{mg}$ once daily thereafter for a total of 28-35 days. ${ }^{27-30}$

\section{ADVERSE EFFECTS}

Most frequent adverse effects documented are bleeding and gastrointestinal events. The common adverse effects documented in clinical studies are anaemia, epistaxis, gastrointestinal haemorrhage, abdominal pain, diarrhoea, 
dyspepsia, and nausea, hepatic function abnormal and urogenital haemorrhage. ${ }^{9,10,27-30}$

\section{CONTRAINDICATIONS}

It is contraindicated in patients with known hypersensitivity to dabigatran or dabigatran etexilate, severe renal impairment with creatinine clearance less than $30 \mathrm{ml} / \mathrm{min}$, haemorrhagic manifestations with bleeding diathesis and concomitant treatment with ketoconazole (systemic). ${ }^{27-31}$

\section{DRUG INTERACTIONS}

Dabigatran etexilate is a substrate of P-glycoprotein efflux transporter. Potent P-glycoprotein inhibitors (systemic ketoconazole amiodarone, and verapamil) increase the plasma concentration and potent Pglycoprotein inducers (rifampicin) reduces it plasma concentration. ${ }^{27-31}$ Therefore dosage adjustments may be required.

\section{SPECIAL POPULATION}

It has been assigned Category $\mathrm{C}$ in pregnancy. There are no adequate and well-controlled studies in pregnancy, fertility and lactation. ${ }^{27-30}$

\section{CONCLUSION}

The current body of clinical evidences indicate that dabigatran etexilate is effective for the prevention and treatment of thrombo-embolic events in patients with acute venous thromboembolism, who are undergoing major orthopaedic (total knee or hip replacement) surgery, or who have atrial fibrillation and represents a giant step forward in the quest to replace conventional anticoagulants.

\section{Funding: None \\ Conflict of interest: None declared \\ Ethical approval: Not required}

\section{REFERENCES}

1. Hawkins D. Limitations of traditional anticoagulants. Pharmacotherapy 2004;24:62S-65S.

2. Kaiser B. Oral antithrombin drugs. In: Kipshidze NN, Moses JW, Fareed J, Serruys PW, eds. Textbook of Interventional Cardiovascular Pharmacology. 1st ed. U.K: Informa Healthcare; 2007: 109-18.

3. Weitz JI. Bloood Coagulation and Anticoagulant, Fibrinolytic and Antiplatelet drugs. In: Brunton LL, Chabner BA, Knollmamn BC, eds. Goodman and Gillman's The Pharmacological Basis of Therapeutics. 12th ed. New York: McGraw Hill; 2011: 849-76.

4. Hauel NH, Nar H, Priepke H, Ries U, Stassen J-M, Wienen W. Structure-based design of novel potent nonpeptide thrombin inhibitors. J Med Chem 2002;45(9):1757-66.

5. Eisert WG, Hauel N, Stangier J, Wienen W, Clemens A, van Ryn J. Dabigatran: an oral novel potent reversible nonpeptide inhibitor of thrombin. Arterioscler Thromb Vasc Biol 2010;10:1885-9.

6. VanRyn J, Stangier J, Haertter S, Liesenfeld KH, Wienen W, Feuring M, et al. Dabigatran etexilate--a novel, reversible, oral direct thrombin inhibitor: interpretation of coagulation assays and reversal of anticoagulant activity. Thromb Haemost 2010;103(6):1116-27.

7. Hankey GJ, Eikelboom JW. Dabigatran etexilate: a new oral thrombin inhibitor. Circulation 2011;123(13):1436-50.

8. Blech S, Ebner T, Ludwig-Schwellinger E, Stangier J, Roth W. The metabolism and disposition of the oral direct thrombin inhibitor, dabigatran, in humans. Drug Metab Dispos 2008;36:386-99.

9. Connolly SJ, Ezekowitz MD, Yusuf S, Eikelboom J, Oldgren J, Parekh A, et al. Dabigatran versus warfarin in patients with atrial fibrillation. N Engl J Med 2009;361(12):1139-51.

10. Connolly SJ, Ezekowitz MD, Yusuf S, Reilly PA, Wallentin L. Newly identified events in the RE-LY trial. N Engl J Med 2010;363:1875-6.

11. Patel P, Sangole N. New oral anticoagulants for stroke prevention in atrial fibrillation: Evidence from phase III clinical trials. Journal of Indian College of Cardiology 2012; 2(3):112-6.

12. Hori M, Connolly SJ, Zhu J, Liu LS, Lau CP, Pais P, Xavier D, et al. Dabigatran Versus Warfarin: Effects on Ischemic and Hemorrhagic Strokes and Bleeding in Asians and Non-Asians With Atrial Fibrillation. Stroke 2013;44(7):1891-1896.

13. Oldgren J, Budaj A, Granger CB, Khder Y, Roberts J, Siegbahn A, et al. Dabigatran vs. placebo in patients with acute coronary syndromes on dual antiplatelet therapy: a randomized, double-blind, phase II trial. Eur Heart J 2011;32(22):2781-9.

14. Eriksson BI, Dahl OE, Rosencher N, Kurth AA, van Dijk CN, Frostick SP, et al. Dabigatran etexilate versus enoxaparin for prevention of venous thromboembolism after total hip replacement: a randomised, double-blind, non-inferiority trial. Lancet 2007;370(9591):949-56.

15. Eriksson BI, Dahl OE, Rosencher N, Kurth AA, van Dijk CN, Frostick SP, et al. Oral dabigatranetexilate vs. subcutaneous enoxaparin for the prevention of venous thromboembolism after total knee replacement: the RE-MODEL randomized trial. J Thromb Haemost 2007;5(11):2178-85.

16. Ginsberg JS, Davidson BL, Comp PC, Francis CW, Friedman RJ, Huo MH, et al. Oral thrombin inhibitor dabigatran etexilate vs North American enoxaparin regimen for prevention of venous thromboembolism after knee arthroplasty surgery. J Arthroplasty 2009;24(1):1-9.

17. Eriksson BI, Dahl OE, Huo MH, Kurth AA, Hantel $\mathrm{S}$, Hermansson $\mathrm{K}$, et al. Oral dabigatran versus 
enoxaparin for thromboprophylaxis after primary total hip arthroplasty (RE-NOVATE II*). A randomised, double-blind, non-inferiority trial. Thromb Haemost 2011;105(4):721-9.

18. Tun NM, Oo TH. Prevention and Treatment of Venous Thromboembolism with New Oral Anticoagulants: A Practical Update for Clinicians. Thrombosis 2013;2013:183616.

19. Schulman S, Kearon C, Kakkar AK, Mismetti P, Schellong, S, Eriksson H, et al. Dabigatran versus warfarin in the treatment of acute venous thromboembolism. N Engl J Med 2009;361(24):2342-52.

20. Schulman S, Kakkar AK, Schellong SM, Goldhaber SZ, Eriksson H, Mismetti P, et al. A randomized trial of dabigatran versus warfarin in the treatment of acute venous thromboembolism (RE-COVER II) ASH Annual Meeting Abstracts. Blood 2011;118:205.

21. Schulman S. Treatment of venous thromboembolism with dabigatran. Curr Opin Pulm Med 2012;18(5):410-5.

22. Schulman S, Kearon C, Kakkar AK, Schellong S, Eriksson H, Baanstra D, et al. Extended use of dabigatran, warfarin, or placebo in venous thromboembolism. N Engl J Med 2013;368(8):70918.

23. Schulman S. Treatment of venous thromboembolism with dabigatran. Curr Opin Pulm Med 2012;18(5):410-5.

24. U.S. Food and Drug Administration. FDA News release: FDA approves Pradaxa to prevent stroke in people with atrial fibrillation Available at: www.fda.gov/NewsEvents/Newsroom/PressAnnoun cements/ucm230241.htm. Accessed 10 March 2013.

25. European Medicines Agency. Summary of the European Public Assessment Report (EPAR) for Pradaxa.

Available http://www.emea.europa.eu/ema/index.jsp?curl=pag es/medicines/human/medicines/000829/human_med _000981.jsp. Accessed 10 March 2013.

26. The Central Drugs Standard Control Organization. New Delhi: Directorate General of Health Services, Ministry of Health and Family Welfare, Government of India. Available at: http://cdsco.nic.in/listofdrugapprovedmain.html. Accessed 10 March 2013.

27. Pradaxa (Dabigatran Etexilate) Indian prescribing information. Mumbai: Boehringer Ingelheim India; February 2013.

28. Global.pradaxa.com. Boehringer Ingelheim: Pradaxa ${ }^{\circledR}$ Summary of Product Characteristics, 2012. Available at: http://vte.pradaxa.com/content/dam/internet/pm/vte/ com_EN/documents/SmPC Jan 2013 after Variation 44 2.doc.pdf. Accessed 4 June 2013.

29. Medsafe. New Zealand Medicines and Medical Devices Safety Authority: Pradaxa (Dabigatran etexilate) New Zealand Datasheet. Available at: http://www.medsafe.govt.nz/profs/datasheet/p/Prada xacap.pdf. Accessed 1 August 2013.

30. Pharmac.govt.nz. New Zealand Datasheet: Pradaxa (Dabigatran etexilate). Available at: http://www.pharmac.govt.nz/2011/07/04/New\%252 0Zealand\%2520Datasheet.pdf/text.

31. RELY-ABLE. Boehringer-Ingelheim and the PHRI, RELY-ABLE Trial Emergency Information: Background data on dabigatran. Available at: https://www.rely-abletrial.com/Rely2Web/resources/jsp/emergency/dabig atran_bg.jsp. Accessed 1 August 2013.

doi: 10.5455/2319-2003.ijbcp20131031

Cite this article as: Jadhav P, Ray I, Vieira A, Ghanekar J, Deshmukh YA. Expanding horizons of anticoagulant therapy: Dabigatran etexilate a novel oral anticoagulant. Int J Basic Clin Pharmacol 2013;2:663-7. 